\title{
Investigating Learners' Acceptability of World Englishes Preferences
}

\author{
Kamonchat Lasote $^{*} \quad$ Janpanit Surasin Denchai Prabjandee \\ Faculty of Education, Burapha University, 169 LongHad Bangsaen RD, Chonburi 20131, Thailand
}

\begin{abstract}
This study aimed to investigate learners' preferences of World Englishes pronunciation, to compare the preferences across gender, and to explore reasons why they prefer a particular pronunciation. The study was conducted at a secondary school in Sa Kaeo province. The participants were 300 upper secondary school learners (Mathayom 4-6). The study used a mixed-methods approach, combining a survey and interviews. To complete the survey, the learners listened to four pronunciations, selected from the three concentric circles by Kachru (1985). The pronunciations consisted of Cambodian, Thai, Filipino, and American. After listening to the pronunciations, the learners rated the level of their preference. The results showed that the learners' preferred the American pronunciation the most. Through semi-structured interview, six informants were requested to explain their justification. It turned out that the main reason behind why the participants preferred a particular pronunciation falls into three reasons: 1) comprehensibility, 2) self-image, and 3) clarity of speech. Moreover, the results also showed that there are no differences in the preferences towards World Englishes pronunciation across gender distinctiveness.
\end{abstract}

Keywords: Learners' Preference, World Englishes Pronunciation

DOI: $10.7176 / \mathrm{JEP} / 11-12-09$

Publication date: April $30^{\text {th }} 2020$

\section{Introduction}

Globalization have brought great changes in the sociolinguistic profiles of English users in the last few years (Prabjandee, 2020). According to Crystal (2004), the number of non-native speakers using English for communication has exceeded the number of native speakers, which means that learners will have more chances to use English with these non-native speakers (Prabjandee, 2020). Kachru and Smith (2008) claimed that these English users contain three types of varieties: 1) those who are used as the primary language of the majority population, 2) those who are used as a secondary language for intranational as well as international communication in communities, and 3) those that are used roughly as a particular language for global communication.

The domination of English around the world has brought up interest on what specific pronunciation should be used, especially in teaching. Similarly, the English language gained different perspectives from all over the world. Each perception varies from each individual that uses the language. In accordance with Holliday (2005) and Kirkpatrick (2010), in general speaking the debates on what pronunciation is naturally better seems to be endless as well as raises arguments not just linguistically but politically. For example, in Thailand, they consider the native pronunciation as superior and the non-native pronunciation as poor (Jindapitak, 2010). In the same manner, another example is how the Japanese considered the American and British pronunciation as exceptional (Matsuda 2000). A study conducted by Scales et al. (2006) resulted in the conclusion that international learners aspire to sound American or British. In contradiction, Matsuda (2003) retaliates that there is no need for Thais to have an American pronunciation to be able to converse with a Filipino at an ASEAN meeting, nor a Japanese man does not need to sound British to communicate his business with a Malaysian. This message clarifies that international English should be addressed with the linguistic conjugation and pluralization.

\section{Statement of the Problem}

The changes in English language teaching cannot be effectively implemented without knowing the learner's voice. This led to the problem about the learners' lack of understanding of their views on pronunciation issues. Teaching English as Foreign Language has a mind-set that is different from the traditional approach based on the linguistic standard, moreover, it is necessary to investigate what are the reasons behind the English language learner's preference of World Englishes pronunciations (Matsuda, 2009). A similar study conducted by Jindapitak (2010), circulates around the Thai preferences on varieties of English, it observed that its participants were English majors from a university in Thailand.

Previous research studies (e.g., Kachru \& Nelson, 2000; 2004; Kim, 2007) were conducted to understand the preferences on World Englishes in the higher education context. This study on the other hand aims to examine the different perceptions of the secondary learners from Sa Kaeo Province towards the varieties of English pronunciation, not just their perceptions but the reasons behind their preferences is an aim of this study. Additionally, this study aimed to compare the learners' acceptability between males and females. Such comparison will be useful for future researchers and other teachers to understand the complexity of the learner's voice about 
English varieties.

\section{Research Questions}

1. What are the Thai English learners' preferences of different World Englishes pronunciation?

2. What are the reasons of learners' preference of a particular World Englishes pronunciation?

3. Are there any differences in the preferences of World Englishes pronunciation across gender distinctiveness?

\section{Literature Review}

Linguistic Imperialism has had a tremendous influence on the English language worldwide (Nordquist, 2019). The spread of English globally is not solely a by-product of politics but also a result of technological innovations (Fennell, 2001). According to Mauranen (2005), English as a lingua franca is a medium of language used in daily communication among people whose first language is not English, this has brought up debates on which pronunciation is more effective: native speaker (NS) or non-native speaker (NNS). The NS varieties of English were always considered before as the most efficient medium in instructional models. Brown (2007) pointed out that the NNS varieties are better in listening, reading or writing skills in English, although NNS varieties may not always acquire the native-like oral proficiency. In addition, Brown (2007) believed that NNS English teachers maximize the use of technology to counterweigh their disadvantage in pronunciation or speaking English. Moreover, Mckay (2002) reckoned that not every single NNS learner has achieved a native-like proficiency. In every international communication, English language is used as a medium. Since Thailand has never been colonized by the British Empire, English in Thailand has always been in a brink. This means that Thais have only if not limited, few involvements with the English language. Thailand is what they call a norm-dependent country which does not own any variety of English or uses English in intercultural interactions. In Thailand there is a great need to learn English since its economy is largely dependent on tourism. This importance is supported by the fact that the English language learning was included in the national curriculum of both primary and secondary schools. Foley (2005) stated that English is a prerequisite to all Thai public university admission. In a study conducted by Mclellan and Wood (2015), English language learning in the Thai context is basically used as a tool "for upward social mobility". Additionally, like any other nationality, Thailand always perceived the NS pronunciation as good, perfect, correct and standard among other varieties of World Englishes. This prevailing ideology of "nativeness" has influenced the Thai learners to cogitate that a way to be a competent English speaker one must procure the native-like pronunciation (Jenkins, 2007). There have been a lot of studies surfacing if there could be differences in the learning process across gender distinctiveness. In the modern and civilized world, the female gender has become more eager to be on the right side of history by seeking political positions, as well as carrying out their rights and opportunities in equal learning. Between the female and male genders, there will always be a variation in language learning with regards to the studies conducted (e.g., Lai, 2007; McKenzie, 2008). The preferences in language and gender vary from each individual culture and historical period, as well as influence from inspirations and models, and lastly are spurred from their phase and setting (Cameron, 2011). In the history of English related studies, Kachru's Three Circled Model of World Englishes has been widely used to classify English speakers throughout the years (Mollin, 2006). This model described the spread of English in a pattern using concentric circles. This model is composed of three circles, the inner circle, outer circle and expanding circle. The inner circle is at the top of the hierarchy, which belonged to the native English speakers (Patil, 2006). The outer circle institutes the non-native speakers from countries where English language is learned as a second language. Finally, in the expanding circle lies the territories where English is learned as a foreign language (Graddol, 2006). Moreover, there has been a rapid growth of learning English around the globe, which has increased the English status in the expanding circle.

\section{Research Design}

The research design of a study outlines the basic approach that researcher uses to answer their research question (Polit \& Beck 2010). In this study, a mixed-methods approach was used to collect adequate and relevant data to address the research questions of this study. This strategy allows to deliberately analyze the data in a successive explanation. The first data to be analyzed was from the quantitative method. The quantitative data addressed the participants' outcomes to provide data related to different speakers' perceptions. The following qualitative data focused on the individual's perception based on their response to different speakers. Both data sets were collected and analyzed separately but connectively. In addition, to accomplish this study, I used a qualitative approach which made use of a phenomenological approach to gather relevant data. This approach concerns more about understanding and interpreting the responses of the participants that will give details about their everyday lives (De Vos, 1998). This approach allowed questioning of respondents, from which I interpreted and understood their feelings based on their responses. This is appropriate for this study because the data that were collected and used had focused on the participants' subjective experiences on the process of revelation and the way they interpreted 
them. Marshall \& Rossman (1995) mentioned that the qualitative approach is suited to explore new avenues.

\section{Data Collection \\ 6.1 Quantitative}

The gathering of data for the quantitative method comes from the participants' survey responses. The questionnaires were given personally to the participants. Since there are 100 participants in each grade, I divided them into two groups per class. Which means there were six sessions in administering the survey: $1^{\text {st }}$ session Mathayomsuksa 4 (50 participants), $2^{\text {nd }}$ session Mathyomsuksa 4 (50 participants), 3rd session Mathayomsuksa 5 (50 participants), $4^{\text {th }}$ session Mathyomsuksa 5 (50 participants), $5^{\text {th }}$ session Mathayomsuksa 6 (50 participants), and $6^{\text {th }}$ session Mathyomsuksa 6 (50 participants). The participants were asked to proceed in a classroom with a conducive environment and free of disturbances. I checked the head count to ensure their attendance. To start with, the participants sat at separate desks and were asked to fill in their demographic information. After that, directions were explained first to make sure that the participants understood the task. If the participants were ready, I played the audio-recording and asked them to listen to it carefully. Since the ratio of the pronunciation and questionnaire is $1: 1$, I played one pronunciation at a time. After they heard the last pronunciation and finished the last page of the questionnaire, I encouraged them to look over their survey questionnaire one more time and put their comments and feedback. I explained to them that their opinions matter in achieving the interest of this study. Thereafter, if everything was completed, the participants could leave the room and I gathered their survey questionnaires.

\subsection{Qualitative}

In this study I used a semi-structured interview. Since there were six informants, I divided them into six sessions: 1. Informant one (positive attitude towards different pronunciation),

2. Informant two (positive attitude toward different pronunciation),

3. Informant three (positive attitude towards different pronunciation),

4. Informant four (negative attitude toward different pronunciation),

5. Informant five (negative attitude towards different pronunciation), and

6. Informant six (negative attitude toward different pronunciation).

Before the interview started, I explained to the informants the process of the interview. In this interview, I used a recording device to have a backup copy of the discussion. Every question was asked in English. There was only one question asked to each informant. For the informants of positive attitudes towards different pronunciation the question was "Why do you prefer this pronunciation?" Meanwhile, the question for the informants of the negative attitudes towards different pronunciations was "Why don't you prefer this pronunciation?"

\section{Data Analysis}

\subsection{Quantitative}

The purposes of the quantitative method were to determine the Thai English learners' preference of World Englishes pronunciation and to compare the preference across gender. To determine the preference, descriptive statistics were used. To compare the preference, an independent $t$-test was performed.

\subsection{Qualitative}

After sorting all the information, first, I gathered the data from the positive attitudes then I drew these data by filtering the significant information needed. Following that I interpreted and analyzed the data. After finishing the data for positive attitudes, I started to break down the information from the negative attitudes. I decided to divide them into two processes: 1 . positive attitude data analyzation, and 2. negative attitude data analyzation. It was appropriate to do for me to fully grasp each process as well as establish an effective conclusion from the analyzed data.

\section{Findings}

First, to solve research question 1. What are the preferences of Thai English learners of different pronunciation? Quantitative findings revealed that the participants chose the American pronunciation as the most preferable, which is a native pronunciation. Participants desire to acquire a native-like pronunciation. In the results in comparison of pronunciations, the participants liked the American pronunciation more. They also tended to have heard the pronunciation before. It is clear from their responses that the participants prefer the American pronunciation the most. 
Table 4: Overall Learner's Preference of World Englishes Pronunciation

\begin{tabular}{|c|c|c|c|c|}
\hline \multirow{2}{*}{ Pronunciation } & \multicolumn{4}{|l|}{$\mathbf{N}=\mathbf{3 0 0}$} \\
\hline & & M & S.D. & Sig. \\
\hline \multirow[t]{2}{*}{ 1. Cambodian } & $1-\mathrm{C}$ & 2.79 & 0.71 & \multirow{2}{*}{$0.01^{*}$} \\
\hline & $2-C$ & 2.79 & 0.67 & \\
\hline \multirow[t]{2}{*}{ 2. Thai } & $1-\mathrm{T}$ & 2.36 & 0.64 & \multirow{2}{*}{$0.00^{*}$} \\
\hline & $2-\mathrm{T}$ & 2.20 & 0.53 & \\
\hline \multirow[t]{2}{*}{ 3. Filipino } & $1-\mathrm{F}$ & 2.88 & 0.51 & \multirow{2}{*}{$0.00^{*}$} \\
\hline & $2-\mathrm{F}$ & 3.11 & 0.56 & \\
\hline \multirow[t]{2}{*}{ 4. American } & $1-\mathrm{A}$ & 3.11 & 0.73 & \multirow{2}{*}{$0.00 *$} \\
\hline & $2-A$ & 3.02 & 0.72 & \\
\hline
\end{tabular}

Second, to address the information to solve research question 2. What are the reasons of learners' preference of World Englishes Pronunciation, the qualitative findings indicate non-native speakers' pronunciation is mostly accepted than native speakers' pronunciation when it comes to the way of speaking and pronunciation. The interviewed informants considered the speaking pace of the speaker as well as its pronunciation. In this case, two out of the six informants chose the American pronunciation by the reason that they like how it sounds. While one of them chose the Filipino pronunciation because it is more comprehensible. Two of the informants considered that Thai pronunciation is less preferable because of its pronunciation and unclear way of delivering the conversation. Aside from that, one informant said that the Cambodian pronunciation was difficult to understand. Finally, with the purpose to solve research question 3. Are there any differences in the preferences of World Englishes Pronunciation across gender distinctiveness? Quantitative data presents that there is no difference with the most preferred and less preferred pronunciation from both genders. Both genders mostly preferred American pronunciation which is for them is the standard pronunciation while the least preferred is Thai pronunciation which is their own acquired pronunciation. It can be concluded that the reason why learners in the class are too shy to speak the language is because they do not like their own pronunciation when speaking the English language.

Table 9: Comparison of Learner's Preferences across Gender Distinctiveness

\begin{tabular}{|c|c|c|c|c|c|}
\hline \multicolumn{3}{|l|}{ Pronunciation } & M & S.D. & \multirow{3}{*}{$\begin{array}{l}\text { Sig. } \\
0.84\end{array}$} \\
\hline \multirow{2}{*}{ 1. Cambodian } & \multirow{2}{*}{$1-\mathrm{C}$} & Male & 2.78 & 0.74 & \\
\hline & & Female & 2.80 & 0.69 & \\
\hline \multirow{2}{*}{ 2. Thai } & \multirow{2}{*}{$1-\mathrm{T}$} & Male & 2.45 & 0.54 & \multirow{2}{*}{0.10} \\
\hline & & Female & 2.32 & 0.68 & \\
\hline \multirow{2}{*}{ 3. Filipino } & \multirow{2}{*}{$1-\mathrm{F}$} & Male & 2.78 & 0.54 & \multirow{2}{*}{0.02} \\
\hline & & Female & 2.93 & 0.49 & \\
\hline \multirow{2}{*}{ 4. American } & \multirow{2}{*}{$1-\mathrm{A}$} & Male & 3.15 & 0.70 & \multirow{2}{*}{0.54} \\
\hline & & Female & 3.09 & 0.74 & \\
\hline \multirow{2}{*}{ 5. Thai } & \multirow{2}{*}{$2-\mathrm{T}$} & Male & 2.30 & 0.49 & \multirow{2}{*}{0.01} \\
\hline & & Female & 2.14 & 0.54 & \\
\hline \multirow{2}{*}{ 6. Cambodian } & \multirow{2}{*}{$2-\mathrm{C}$} & Male & 2.76 & 0.68 & \multirow{2}{*}{0.62} \\
\hline & & Female & 2.80 & 0.66 & \\
\hline \multirow{2}{*}{ 7. American } & \multirow{2}{*}{$2-\mathrm{A}$} & Male & 3.07 & 0.77 & \multirow{2}{*}{0.42} \\
\hline & & Female & 2.99 & 0.70 & \\
\hline \multirow{2}{*}{ 8. Filipino } & \multirow{2}{*}{$2-\mathrm{F}$} & Male & 2.86 & 0.56 & \multirow{2}{*}{0.55} \\
\hline & & Female & 2.90 & 0.55 & \\
\hline
\end{tabular}

Therefore, although the participants are all non-native speakers, they undoubtedly would want to acquire the native speaker pronunciation because it is known as the standard pronunciation. In addition, based on other participants, pronunciation is a key to have better English pronunciation. They claimed that, although they like the pronunciation of the native speaker, they still would want to speak in a fluent, slow and comprehensible manner. Hence, it is clear that participants can easily grasp the idea with the speaker who has clear pronunciation and has a slow speech pace like non-native speakers.

\section{Discussion}

\subsection{Thai Learners' Preferences of World Englishes Pronunciation}

The global spread of English has posed new challenges to traditional English language learning and teaching, particularly in countries where English in normally treated as a foreign language. According to Schneider (2003), English in Thailand is still not considered as fully developed. In this case, Thais mostly disassociate themselves with the English language. At present, it is mandatory for Thai learners to study English beginning at first grade (Wongsothorn, et al., 2003). This study is focused on investigating the Thai learners' preference of World Englishes pronunciation. From the results, the majority of the participants opted for the American pronunciation 
as their most preferred pronunciation. The data illustrated that the participants' desire in choosing the American pronunciation is based on the participants' beliefs that in order to speak English fluently, one must sound like a native speaker. Moreover, some of the feedback generated from the participants, explained that although the American pronunciation is fast and difficult to understand because of the pronunciation, they still prefer the pronunciation because it is the standard pronunciation. Additionally, the participants ranked the Filipino pronunciation as the second-best preferred pronunciation of the recordings, despite that the Filipino pronunciation has a slow speaking-pace and is comprehensible, it is still not the standard pronunciation. The discussed results show that the Thai learners despised their very own pronunciation; Thai pronunciation. In Thailand, arguments on what specific pronunciation should be used in classroom management and teaching are prevalent. In line with that, this discussion could enlighten anyone who teaches English, that for the learners, they are well motivated and inspired with the American pronunciation as a medium in teaching and learning English language.

\subsection{Reasons of Learners' Preferences of World Englishes Pronunciation}

Knowledge of learners' reasons behind preferences on World Englishes can help improve the teaching and learning process of English language. As specified by Matsuda (2003), inadequate exposure to varieties of English may confuse learners and repel linguistic variations when they encounter different types of English uses and users in legitimate circumstances. This study aims to examine and explore the reasons behind the learners' preferences on World Englishes pronunciation. Through In-Depth Interview, six informants were requested and encouraged to explain their justification. It turned out that the main reason behind why the participants preferred the American pronunciation is that it is the standard pronunciation. This idea is supported by Holmes (2008), who stated that people most likely comprehend better when they listen to the speaker they adore. It is clear that the participants idolize the American pronunciation, even if they could hardly understand the speaker. The results discussed in this study also state that the speaker's speech pace is also considered by the participants as one of the reasons for their preferences. All language learners should be prepared for imminent engagements with speakers of varieties of English that contradicts their own (Jenkins, 2000).

\subsection{Differences in the Preferences across Gender Distinctiveness}

Debates on gender are exceedingly abundant and can be found in many different areas. As stated by Talbot (2010), English is not homogeneous. Given the fact that males and females are distinctive, the variation between males and females in the form of language is used as cultural manifestation. In this study, the results showed that there are no differences in the preferences towards World Englishes pronunciation across gender distinctiveness. Both genders: males and females, have the same ideology. Although the participants are non-native speakers, both males and females collectively despise their own Thai pronunciation. The participants stated that they do not like the Thai pronunciation in speaking English. However, in establishing what pronunciation is considered as the second most preferred pronunciation, there are valid variations between the preference of males and females. In this case, there is a slight difference in these preferences across gender distinctiveness. Since learners vary from their intelligence, it is important to explore on the gender biases. Through this, the teaching and learning English process could use more appropriate pedagogy.

\section{Implication}

In line with this study, it revolves in investigating the learner's preference of World Englishes pronunciation. It explains and provides more information to people that do not know much about the learners' preferences. The results of this study can benefit any person to look deeper on how pronunciation affects learning and understanding. Though this study mainly focuses on the learners' desired pronunciation to make their learning more interesting, this study might as well give ideas to schools that American pronunciation might be well accepted but there are other pronunciations that can cater well to the learners' needs. This study is a great help in determining what pronunciation to follow or most likely to apply in practice. In relation with the results, it can be of help in empowering the Thai pronunciation more. Thai learners seemed to be a little reluctant in speaking English for they are afraid to sound funny. In the result of this study, I found out that the learners most undesirable pronunciation is the Thai pronunciation, in which through this research can enhance and practice more to be better and be more confident. Aside from that, this study will give meaning to the confusion of the pronunciation norms. More importantly this study can encourage the teachers to improve their English pronunciation.

\section{Recommendation for the further studies}

In the reckoning that the researcher would go an extra mile, he or she could do as follows. First, compare more pronunciations. Expand the geographic plan of the study. It will create a more interesting study if not only Asian countries are considered in the study. The British pronunciation would do well in the comparison of the American pronunciation. This will also create a more varied and wide research results. Second, focus on the heterogeneous comparisons. Aside from gathering data in one single school try to explore the schools that have foreign English 
teachers. These participants would be a great help in the diversity of the study, providing not just one coherent answer but more assortment. Third, one must determine the goals and objectives. The more questions asked the better the results. In terms of interpreting the data collected, it would be much more profound if there were more instruments used. The instruments serve as a spring board in data collection. Fourth, this study provides data that there are learners who would rather learn with a non-native speaker pronunciation rather with a native speaker pronunciation. This is because non-native pronunciation is better and more comprehensible than the native pronunciation. This result could generate much more interesting research if one can provide more arguments and justification from the participants.

\section{References}

Brown, H. D. (2007). Teaching by principles: An interactive approach to language pedagogy (3rd ed.). New York: Pearson Education.

Cameron, D. (2011). Gender and language ideologies. In J. Coates, \& P. Pichler (Eds.), Language and gender: A reader (2nd ed., pp. 583-599). New York: Routledge

Crystal, D. (2004). The language revolution. Cambridge: Polity.

De Vos, A. S. (1998). Conceptualisation and operationalisation. In A. S. De Vos, E. M. Schurink, \& H. Strydom (Eds.), Research at grass roots: A primer for the caring professions. Pretoria: Van Schaik.

Foley, J. (2005). English in Thailand. RELC Journal, 36(2), 223-234.

Graddol, D. (2006). English next: Why global English may mean the end of English as a foreign language. London: British Council.

Holliday, A. (2005). The struggle to teach English as an international language. Oxford: Oxford University Press.

Holmes, J. (2008). An introduction to sociolinguistics. Essex: Pearson Education.

Jenkins, J. (2007). English as lingua franca: Attitudes and identity. Oxford: Oxford University Press.

Jindapitak. N. (2010). An attitudinal study of varieties of English: Voices from Thai University English learners. Master's thesis, Department of Languages and Linguistics, Faculty of Liberal Arts, Prince of Songkla University.

Kachru, B. B. (1985). Standards, codification and sociolinguistic realism: The English

Kachru, Y., \& Nelson, C. (2006). World Englishes in Asian contexts. Hong Kong: HongKong University Press.

Kachru, Y., \& Smith, L. E. (2008). Cultures, contexts, and world Englishes. New York: Routledge.

Kim, Y. (2007). Korean attitude towards varieties of English. Master's thesis, Department of Applied Linguistics, College of Languages, Princess Nowrah bint Abdhulraman University.

Kirkpatrick, A. (2010). English as a lingua franca in ASEAN: A multilingual model. Hong Kong: Hong Kong University Press.

Lai, M. L. (2007). Gender and language attitudes: A case of postcolonial Hong Kong. International Journal of Multilingualism, 4(2), 83-116. language in the outer circle. In R. Quirk, \& H. Widdowson (Eds.), English in the world, teaching and learning the language and literatures (pp. 11-30). Cambridge: Cambridge University Press

Marshall, C., \& Rossman, G. B. (1995). Designing qualitative research (2nd ed.) Thousand Oaks: Sage.

Matsuda, A. (2000). Japanese attitudes towards English: A case study of high school students. Doctoral dissertation, Purdue University.

Matsuda, A. (2003). Incorporating world Englishes in teaching English as an international language. TESOL Quarterly, 37(4), 719-729.

Matsuda, A. (2009). Desirable but not necessary? The place of world Englishes and English as an international language in English teacher preparation programs in Japan. In F. Sharifaian (Ed.), English as an international language: Perspectives and pedagogical issues (pp. 169-189). Bristol: Multilingual Matters.

Mauranen, A. (2005). The corpus of English as lingua franca in academic settings. TESOL Quarterly, 37, 513527.

McKay, S. L. (2002). Teaching English as an international language: Rethinking goals and approaches. Oxford: Oxford University Press.

Mckenzie, R. (2008). Social factors and non-native attitudes towards varieties of spoken English: A Japanese case study. International Journal of Applied Linguistics, 18(1), 63-88.

McLellan, J., \& Wood, A. (2015). Introduction. In T. Bigalke, \& S. Sharbawi (Eds.), English for ASEAN integration: Policies and practices in the region (pp. 7-11). Bandar Seri Begawan: University Brunei Darussalam.

Mollin, S. (2006). Euro-English: Assessing variety status. Tübingen: Narr.

Nordquist, R. (2019). The Sapir-Whorf hypothesis linguistic theory. Retrieved form https://www.thoughtco.com/sapir-whorf-hypothesis-1691924

Patil, N. Z. (2006). On the nature and role of English in Asia. The Linguistics Journal 1(2), 88-131.

Polit, D. F., \& Beck, C. T. (2010). Essentials of nursing research: Appraising evidence for nursing practice (7th 
ed.). Philadelphia: Wolters Kluwer Health/ Lippincott Williams \& Wilkins.

Prabjandee, D. (2020) Teacher professional development to implement Global Englishes language teaching. Asian Englishes, 22(1), 52-67.

Scales, J., Wennerstorm, A., Richard, D., \& Wu, S. H. (2006). Language learners' perceptions of pronunciation. TESOL Quarterly, 40(4), 715-738.

Schneider, E. W. (2003). The dynamics of new Englishes: From identity construction to dialect rebirth. Language, 79(2), 233-281.

Talbot, M. (2010). Language and gender. New York: Polity Press.

Wongsothorn, A., Hiranburana, K., \& Chinnawongs, S. (2003). English language teaching in Thailand today, in English language teaching. In W. K. Ho, \& R. Y. L. Wong (Eds.), East Asia today: Changing policies and practices (pp. 441-453). Singapore: Eastern Universities’ Press. 